\title{
Cortical and STN spectral changes during limb movements in PD patients with and without dystonia
}

Arie Nakhmani ${ }^{1 \dagger}, \mathrm{PhD}$, Joseph W. Olson ${ }^{2 \dagger}, \mathrm{PhD}$, Zachary T. Irwin ${ }^{3}, \mathrm{PhD}$, Lloyd J. Edwards ${ }^{4}$, PhD, Christopher L. Gonzalez², MS, Melissa H. Wade ${ }^{2}$, CRNP, Sarah D. Black $^{3}$, MS, Mohammad Z. Awad ${ }^{1}$, MS, Daniel J. Kuhman ${ }^{5}$, PhD, Christopher P. Hurt ${ }^{5}$, PhD, Bart L. Guthrie ${ }^{3}, \mathrm{MD}$, Harrison C. Walker ${ }^{2 \star}, \mathrm{MD}$

${ }^{1}$ Department of Electrical and Computer Engineering, University of Alabama at Birmingham, Birmingham, Alabama 35294

${ }^{2}$ Department of Neurology, University of Alabama at Birmingham, Birmingham, Alabama 35294

${ }^{3}$ Department of Neurosurgery, University of Alabama at Birmingham, Birmingham, Alabama 35294

${ }^{4}$ Department of Biostatistics, University of Alabama at Birmingham, Birmingham, Alabama 35294

${ }^{5}$ Department of Physical Therapy, University of Alabama at Birmingham, Birmingham, Alabama 35294

${ }^{\dagger}$ Equal contribution

${ }^{*}$ Correspondence:

Harrison C. Walker

hcwalker@uabmc.edu 
medRxiv preprint doi: https://doi.org/10.1101/2022.01.04.22268757; this version posted January 6, 2022. The copyright holder for this preprint (which was not certified by peer review) is the author/funder, who has granted medRxiv a license to display the preprint in perpetuity.

\section{ABSTRACT}

Background: Dystonia is a prevalent yet under-studied motor feature of Parkinson disease (PD). Although considerable efforts have focused on brain oscillations related to the cardinal symptoms of PD, whether dystonia is associated with specific electrophysiological features is unclear.

Objectives: To investigate subcortical and cortical field potentials at rest and during contralateral hand and foot movements in PD patients with versus without dystonia.

Methods: We examined the prevalence and somatotopy of dystonia in PD patients undergoing deep brain stimulation (DBS) surgery. We recorded intracranial electrophysiology from sensorimotor cortex and directional DBS electrodes in subthalamic nucleus (STN), during both rest and voluntary contralateral limb movements. We used wavelet transforms and linear mixed models to characterize spectral content in patients with and without dystonia $(n=25)$.

Results: Dystonia was highly prevalent at enrollment (61\%) and most common in the foot $(78 \%)$. PD patients with dystonia display greater subthalamic theta and alpha power during movement $(p<0.05)$ but not at rest. Regardless of dystonia status, cortical recordings display prominent beta desynchronization $(13-30 \mathrm{~Hz})$ during movement, whereas STN signals show increases in spectral power at lower frequencies $(4-20 \mathrm{~Hz})$, with peaks at $6.0 \pm 3.3$ and $4.2 \pm 2.9 \mathrm{~Hz}$ during hand and foot movements, respectively $(\mathrm{p}<$ 0.03).

Conclusions: Whereas cortex was characterized by beta desynchronization during hand and foot movements similarly, STN showed limb-specific low frequency activity which was increased in PD patients with dystonia. These findings may help elucidate why PDrelated dystonia is most common in the foot and help guide future closed-loop DBS devices. 
medRxiv preprint doi: https://doi.org/10.1101/2022.01.04.22268757; this version posted January 6, 2022. The copyright holder for this preprint (which was not certified by peer review) is the author/funder, who has granted medRxiv a license to display the preprint in perpetuity. All rights reserved. No reuse allowed without permission.

\section{INTRODUCTION}

Dystonia - a twisting, sustained, and often painful involuntary movement - is an under studied motor manifestation of Parkinson disease (PD) [1, 2, 3, 4]. A hallmark of young onset PD, dystonia commonly begins in the foot on the more affected side of the body and spreads to other anatomic locations with disease progression [5, 6, 7, 8]. Accurate estimates of the prevalence of PD-related dystonia have been difficult to obtain. Dystonia may be a presenting symptom of PD in younger patients, with prior studies estimating prevalence of $14-50 \%$ in young onset PD patients. PD patients with the parkin mutation have a higher prevalence estimated around 78\% [9]. About 30\% of levodopa-treated PD patients have some form of dystonia [1], and dystonia severity increases with duration of disease with 2,12 , and $56 \%$ prevalence at $<5,6-9$, and $>10$ years duration, respectively [10].

Deep brain stimulation (DBS) of the subthalamic nucleus (STN) is an effective treatment for dystonia related to PD [11, 12, 13], however little is known about its circuit-level electrophysiology. More is known about the electrophysiology of primary dystonia. Growing evidence suggests that primary dystonia is marked by excessive theta and alpha oscillations $(<13 \mathrm{~Hz})$ in globus pallidus interna (GPi) at rest, while PD has been associated with excessive power in the beta frequency range $(13-30 \mathrm{~Hz})[14,15,16,17,18,19,20$, $21,22]$. A recent meta-analysis suggests the STN has similar increases in theta and alpha power at rest in primary dystonia compared to PD, with no significant differences in the beta band [23, 24, 25, 26]. Resting local field potentials (LFPs) in primary motor cortex (M1) did not differ significantly for any frequency band in the same meta-analysis $[23,21,27,28]$. To our knowledge, no studies have compared cortical and subcortical LFPs in PD patients with and without dystonia as an accompanying symptom.

Several studies have evaluated changes in LFPs in sensorimotor cortex and basal ganglia in PD patients both at rest and during hand movements. Most report beta desynchronization during movement followed by beta rebound [29]. Compared to upper limb movements, electrophysiology of lower limb movements in PD patients are less characterized. Scalp recordings show beta and gamma frequencies are activated somatotopically at low frequencies during walking and foot flexions in PD patients [30, 31, 32, 33, 34, 35, 36]. Considerably less is known about LFP changes in basal ganglia. Some recent studies report lower limb and upper limb movement onset coincides with high and low beta desynchronization respectively in both STN and motor cortex [37, 38, 39]; however, studies utilizing DBS systems with embedded sensing capabilities report mixed results regarding STN beta desynchronization during walking [30, 40, 41, 42]. Furthermore, low frequency oscillations in basal ganglia may be modulated during walking $[30,43]$. Lower extremity symptoms can be more resistant to therapy versus arm symptoms. Declines in gait, balance, and posture are important unmet needs for therapy in advanced PD, regardless of the presence or absence of dystonia. Therefore, greater mechanistic knowledge about changes in field potentials during specific limb movements (i.e., upper versus lower extremity) could lead to novel strategies for therapy with nextgeneration open- and closed-loop directional DBS devices. 
medRxiv preprint doi: https://doi.org/10.1101/2022.01.04.22268757; this version posted January 6, 2022. The copyright holder for this preprint (which was not certified by peer review) is the author/funder, who has granted medRxiv a license to display the preprint in perpetuity. All rights reserved. No reuse allowed without permission.

Here we investigate LFPs recorded in parallel from sensorimotor cortex and STN during DBS surgery in PD patients with and without dystonia. We recorded neural activity from an electrocorticography (ECoG) strip over the 'hand knob' of sensorimotor cortex and a directional DBS lead placed at dorsolateral STN, both at rest and during simple repetitive voluntary hand and foot movements. Our goals were to contrast the underlying signals in PD patients with and without dystonia and then to examine subcortical and cortical spectral perturbations at rest and during contralateral hand and foot movements.

\section{METHODS}

\section{Recruitment and enrollment}

Participants were recruited and studied prospectively as part of the SUNDIAL (SUbthalamic Nucleus DIrectionAL stimulation) study, a randomized, double-blind crossover study contrasting directional versus circular unilateral STN DBS for PD (FDA Investigational Device Exemption G-170063, ClinicalTrials.org Identifier: NCT03353688). All subjects provided written informed consent prior to participation with approval from the institutional review board. We included data from all consecutively enrolled participants.

\section{Behavioral testing}

We measured PD motor symptoms with normed, validated clinical instruments, including MDS-UPDRS part 3 and part 4 item 6 (painful 'off' dystonia question). There are no comprehensive dystonia rating scales related specifically to PD, therefore we used the Burke-Fahn-Marsden (BFM) dystonia scale to characterize its severity and anatomic distribution [44]. These measures were obtained in a pre-operative baseline screening visit and longitudinally at 2 and 4 months after surgery in the practically defined "off" medication state (off dopaminergic medications $>12$ hours). Additionally, we determined the presence of dystonia during DBS surgery through neurological examination.

During surgery, patients were instructed to rest comfortably during two separate nonconsecutive intervals of one minute duration each. Verbal instructions for moving the contralateral hand or foot were "open and close your hand as big and fast as possible when you are told 'go' until the examiner says 'stop'," and "repetitively move your toes and ankle when you are told 'go' until the examiner says 'stop'." Button press signals corresponded to verbal commands from the examiner ("ready", "set", "go", and "stop"). Hand and foot movements were both recorded in non-consecutive 10 seconds blocks, with 2 repetitions each. Therefore, the total recording time for rest, foot movement, and hand movement conditions was approximately 2 minutes and 40 seconds (with additional transition time for verbal instructions). Rest and movement intervals were validated posthoc based upon visualization of EMG recordings.

\section{Electrophysiological recordings and neuroimaging}

In our practice, DBS surgeries are conducted unilaterally with the patient awake and "off" dopaminergic medications. We recorded LFPs simultaneously from the DBS lead in its final target location in STN and linear 6-contact ECoG strip placed temporarily over the hand knob area of ipsilateral sensorimotor cortex (Figure 1A). The directional DBS lead 
A

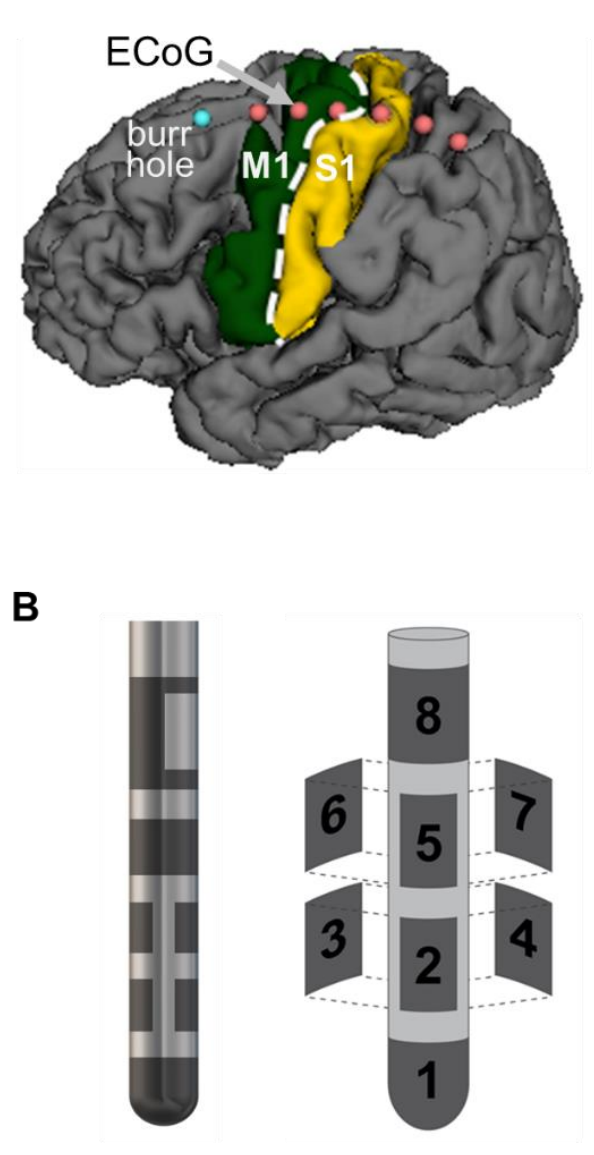

C S1 ECoG (rest)
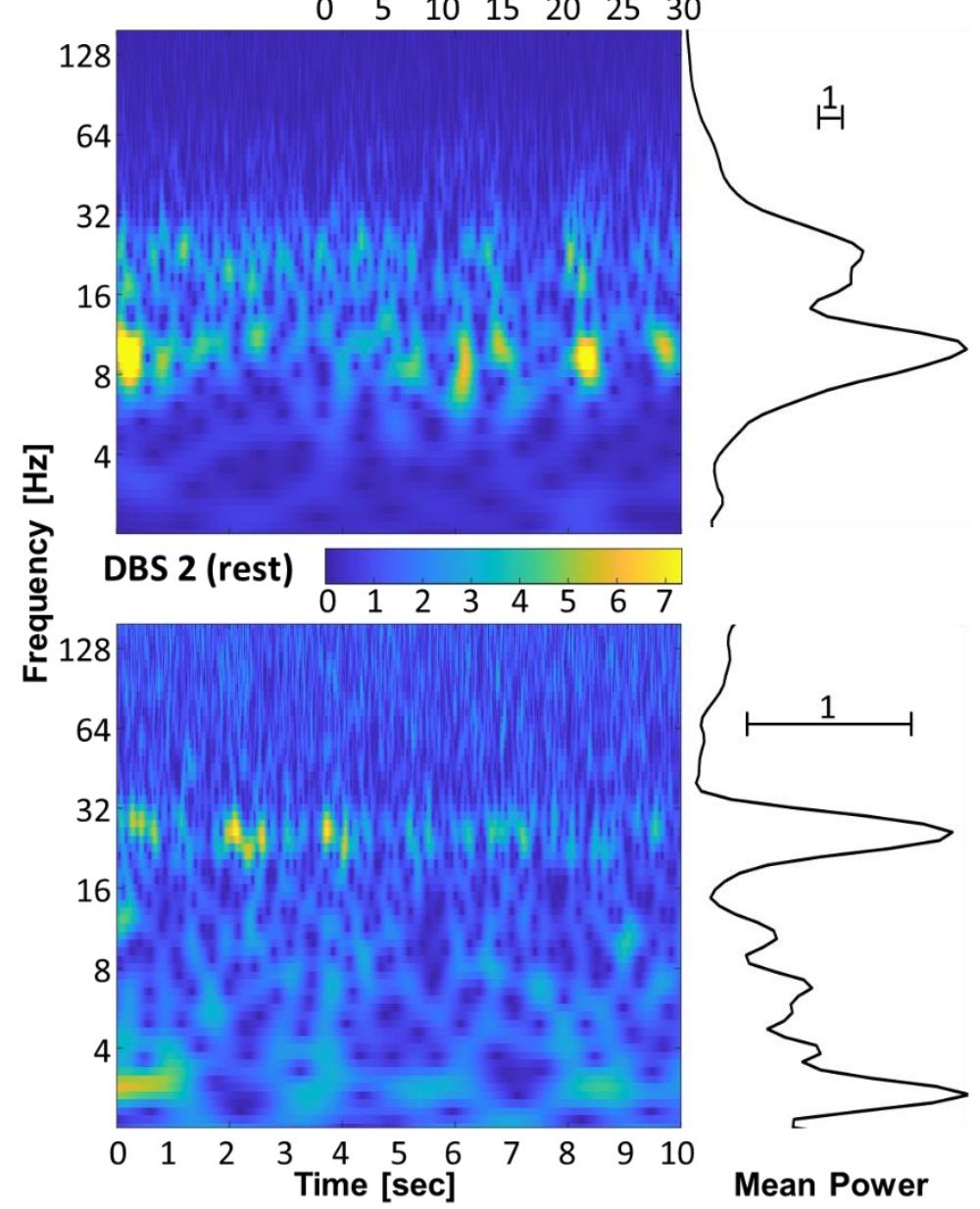

Mean Power

FIGURE 1. Cortical and subcortical signal recording. (A) M1 and S1 regions are overlayed on segmented brain from a pre-op MRI scan. The ECoG strip with 6 contacts is placed over the hand knob area of primary sensorimotor cortex (contacts are outlined in red). It is inserted through the burr hole (blue) during a surgical DBS procedure. (B) Directional DBS electrode organization with two rings and two rows of 3 contacts each (1-3-3-1). It is placed along the dorsolateral border of STN as part of routine care. (C) Resting state wavelet scalogram example from S1 (above) and DBS contact 2 (below) for a single participant. The mean spectral power estimated on the right is computed by averaging each row of the scalogram over time.

(Boston Scientific's Vercise Cartesia ${ }^{\mathrm{TM}}$ directional lead) consists of 8 contacts arranged into 4 rows, each separated by $0.5 \mathrm{~mm}$ in a '1-3-3-1' configuration (Figure 1B). The lead is placed such that the dorsolateral border of STN lies between the two middle rows of with contacts 2 and 5 facing anteriorly. We sampled all signals continuously at $25 \mathrm{kHz}$ with appropriate digital filters using a BrainVision actiChamp amplifier. We acquired surface electromyography (EMG) recordings from contralateral first dorsal interosseous, flexor carpi radialis, and gastrocnemius muscles. 
medRxiv preprint doi: https://doi.org/10.1101/2022.01.04.22268757; this version posted January 6, 2022. The copyright holder for this preprint (which was not certified by peer review) is the author/funder, who has granted medRxiv a license to display the preprint in perpetuity. All rights reserved. No reuse allowed without permission.

Pre-op MAGNETOM Prisma MRI scans were segmented with FreeSurfer (Harvard, Martinos Center for Biomedical Imaging) and registered with intra-op O-arm CT for the anatomical localization of ECoG contacts [45]. Because the Boston Scientific DBS lead was not approved for use with MRI at the time of this study, high-resolution post-op CT was obtained to verify anterior orientation of contacts 2 and 5 on the DBS lead with LeadDBS [46]. We classified ECoG contacts based on the anatomical brain region each overlay as identified by FreeSurfer. These regions included dorsal premotor cortex (dPMC), supplementary motor area (SMA), primary motor cortex (M1), primary somatosensory cortex (S1), or secondary somatosensory cortex (S2/S3). Directional DBS contacts were classified by row and into medial, anterior, and lateral orientations based on implant hemisphere.

\section{Digital signal processing and analysis}

Signal processing was performed using in-house MATLAB (R2020a; MathWorks, Natick, MA) code and EEGLAB toolbox (UC San Diego, Swartz Center for Computational Neuroscience) [47]. To verify data integrity, we confirmed normal tissue impedance, visualized the raw continuous signals, and generated spectral plots with continuous Morse wavelet transforms (MATLAB function 'cwt') on all channels. Invalid signals were excluded from subsequent analyses. We re-referenced ECoG and DBS signals using common average reference. We analyzed all available signals across recording modalities, totaling as many as 14 recording sites plus 3 EMG electrodes per participant.

We visualized the LFPs in two ways. First, we generated wavelet scalograms for each contact and then averaged the scalograms over time to obtain spectral magnitude (henceforth called power) across relevant frequencies (Figure 1C). To avoid edge artifacts in the wavelet transform computation, we included 2 seconds before and after the movement block, computed the wavelet transform with the expanded signal, and then removed the 4 seconds padding. Second, we compared the spectra from each DBS and ECoG location at rest and during hand and foot movements with and without dystonia. We define frequency ranges for the field potentials as follows: delta (0.5-4 Hz), theta (4$8 \mathrm{~Hz}$ ), alpha $(8-13 \mathrm{~Hz})$, beta $(13-30 \mathrm{~Hz})$, gamma $(30-70 \mathrm{~Hz})$, and high frequency broadband (hfb) (70-160 Hz).

\section{Statistical approach}

Descriptive statistics including mean, standard deviation, minimum, maximum, and 95\% CI were computed for LFP spectral power averaged across all valid contacts within each frequency band for foot, hand, and rest. For each frequency band, we used paired t-tests to compare spectral power during hand and foot movements both to rest and to each other (Figure 3A). To assess spectral differences between patients with or without dystonia (Figure 5), we used linear mixed models [48, 49] with dichotomous predictor for dystonia status, 4th-degree natural polynomials for log-transformed frequency, and the interaction between dystonia status and polynomials as fixed effects to model the wavelet spectrum averages for all recorded channels. Subject-specific intercepts were included as random effects. We identified statistically significant differences between spectrum intervals by identifying overlap within $95 \%$ confidence intervals. Linear mixed models 
medRxiv preprint doi: https://doi.org/10.1101/2022.01.04.22268757; this version posted January 6, 2022. The copyright holder for this preprint (which was not certified by peer review) is the author/funder, who has granted medRxiv a license to display the preprint in perpetuity.

All rights reserved. No reuse allowed without permission.

were fitted for foot, hand, and rest and Cls were compared based on UPDRS item 4.6, BFM, and surgical exam.

\section{Data Sharing}

All data is available on the Data Archive for the Brain Initiative (DABI) at https://dabi.loni.usc.edu/home.

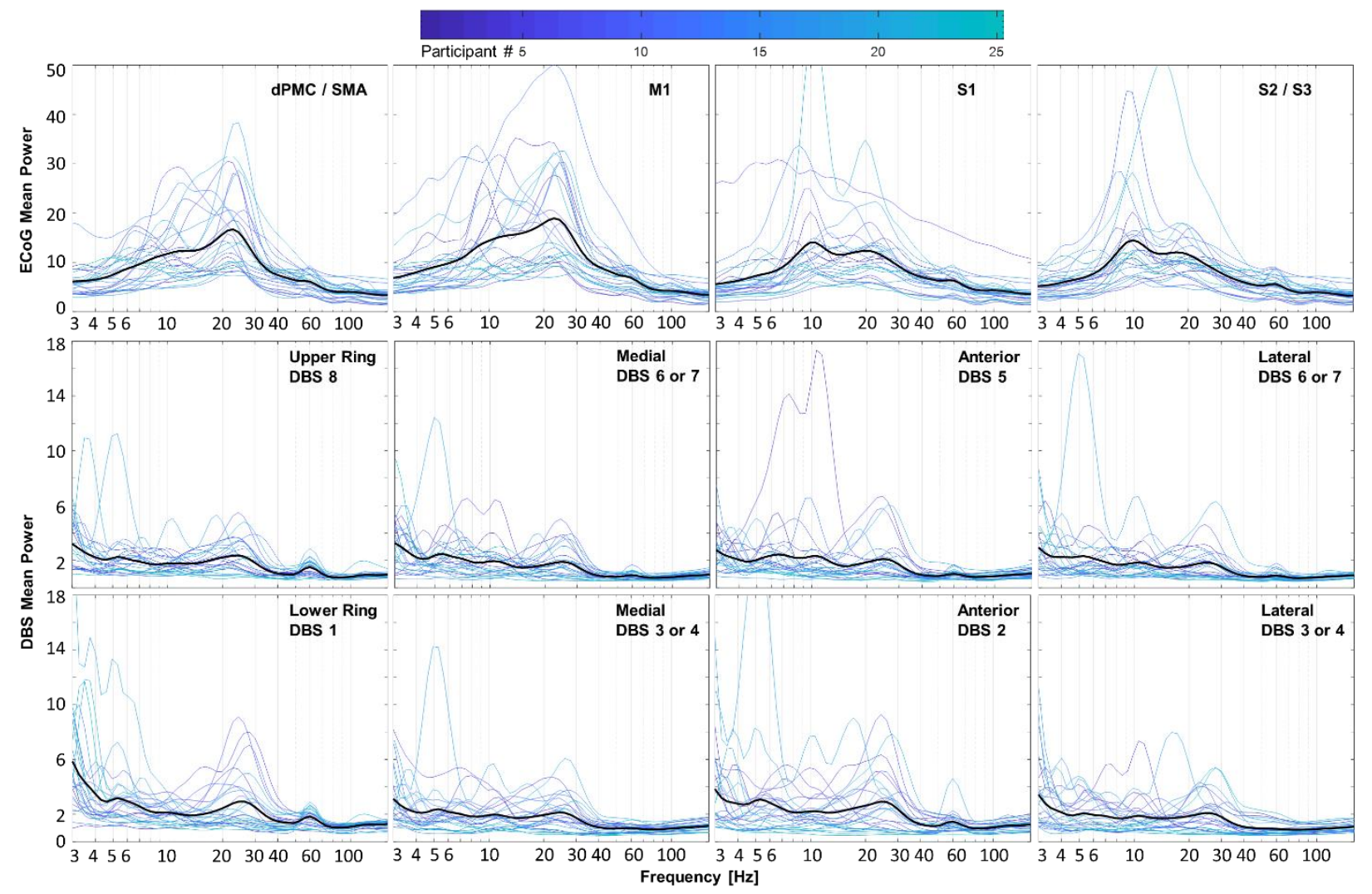

FIGURE 2. Cortical and subcortical field potentials at rest in PD participants. Spectral power from all electrode contacts over ipsilateral cortex (first row) and the STN region (second and third row) are categorized by anatomical location obtained from imaging, regardless of dystonia status. For each location, there is one plot per participant color-coded by participant number. Means are represented by darker black lines. Beta frequency power is present and relatively large in essentially all electrocorticography contacts, whereas lower beta power is present in most but not all DBS contacts, along with greater relative power at lower frequencies. 
medRxiv preprint doi: https://doi.org/10.1101/2022.01.04.22268757; this version posted January 6, 2022. The copyright holder for this preprint (which was not certified by peer review) is the author/funder, who has granted medRxiv a license to display the preprint in perpetuity.

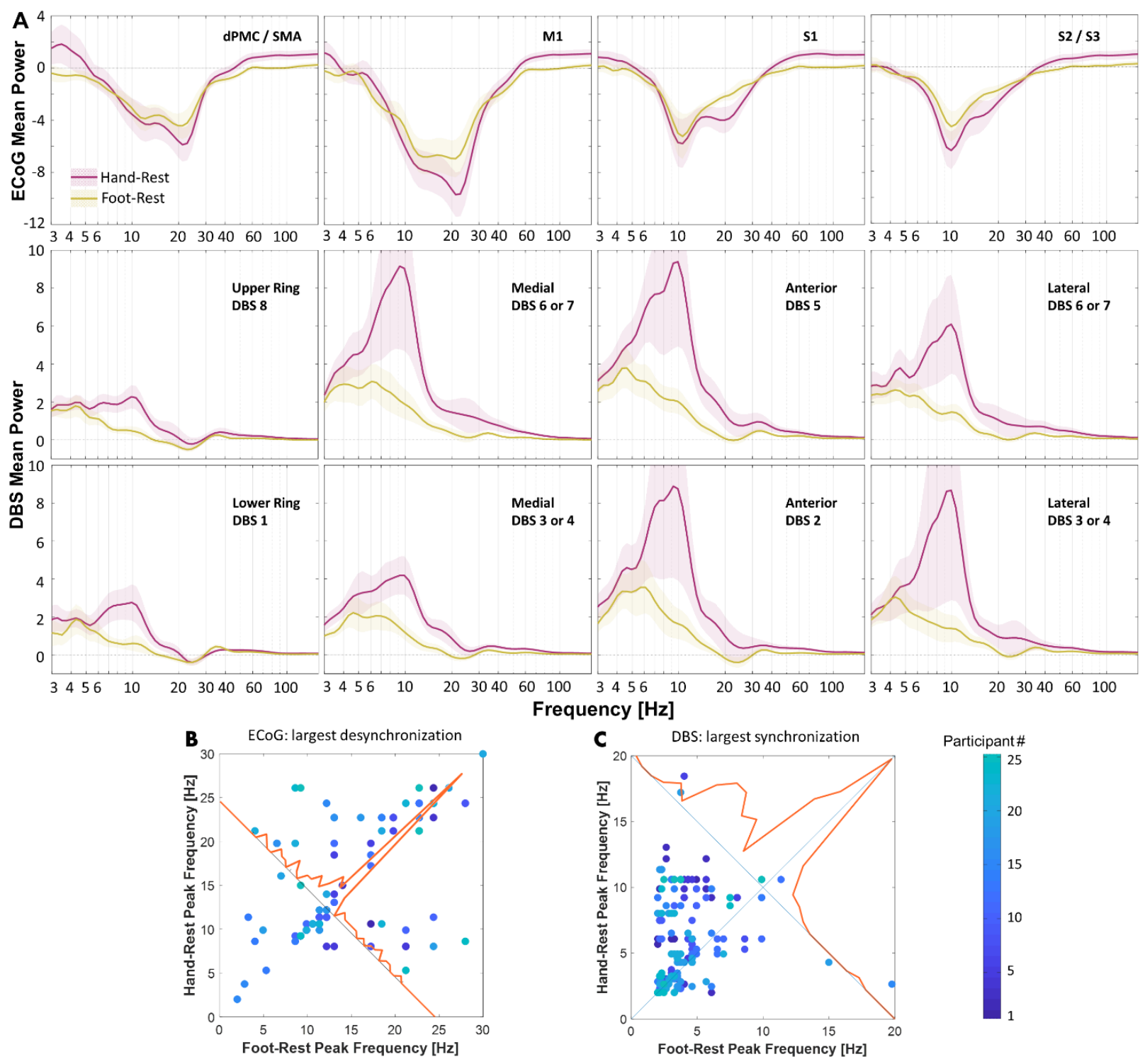

FIGURE 3. Cortical and subcortical spectral perturbations in PD participants during continuous, repetitive hand and foot movements minus rest. (A) Spectral power for all participants $(n=25)$ and recording sites are summarized in row 1 for sensorimotor cortex and rows 2 and 3 for dorsal and ventral DBS contacts (mean across participants \pm standard error). Red and yellow traces correspond to hand and foot signals, respectively. (B, C) Frequencies that displayed the strongest deviations during movement versus rest in cortex and STN (i.e., either desynchronization or synchronization). If the spectral perturbations are identical, observations will appear on or near the unity line (diagonal line). (B) Frequencies corresponding to power minima in IPMC/SMA, M1, S1, S2/S3 contacts during foot versus hand movements. (C) Frequencies corresponding to power maxima from all DBS contacts during foot versus hand movements. 
medRxiv preprint doi: https://doi.org/10.1101/2022.01.04.22268757; this version posted January 6, 2022. The copyright holder for this preprint (which was not certified by peer review) is the author/funder, who has granted medRxiv a license to display the preprint in perpetuity. All rights reserved. No reuse allowed without permission.

\section{RESULTS}

\section{Demographics}

We studied intraoperative LFPs in 28 of 38 (74\%) participants who met entry criteria for the SUNDIAL trial. Exclusions related to the following: $\leq 30 \%$ improvement UPDRS part 3 "on" versus "off" PD medications $(n=4)$; Beck Depression Inventory >10 $(n=1)$; multidisciplinary committee recommended globus pallidus rather than STN target $(n=2)$; medical condition requiring future $\mathrm{MRI}(n=1)$; health insurance refused payment for surgery with an investigational device $(n=1)$; and voluntary withdrawal $(n=1)$. Of the 28 participants with recorded LFPs, 3 had corrupted or missing data, yielding 25 participants for subsequent analyses.

\section{Resting state field potentials}

Spectral analyses of resting field potentials revealed peaks in the beta frequency range (13-30 Hz) in both sensoricortex and STN, with approximately five times the magnitude at cortical recording sites (Figure 2). Additionally, cortical spectra show an anterior to posterior gradient of peak frequencies, with high beta activity $(>20 \mathrm{~Hz})$ at dPMC/SMA and $\mathrm{M} 1$ and lower beta and alpha activity at $\mathrm{S} 1$ and more posterior recordings sites.

\section{Spectral perturbations during hand and foot movements}

To isolate changes in spectral power related to movement, we subtracted resting spectra from movement spectra within each channel (Figure 3A). Cortical LFPs demonstrate broadband power changes during repetitive voluntary hand and foot movements compared to rest. Alpha and beta power of cortical LFPs decrease markedly during both movements, while hfb power increases during hand movements only (Foot. theta: -1.0 $\pm 1.9, \mathrm{p}=0.014$; alpha: $-4.0 \pm 3.8, \mathrm{p}<0.001$; beta: $-3.4 \pm 2.3, \mathrm{p}<0.001$; gamma: $-0.6 \pm 0.9$, $\mathrm{p}=0.004$. Hand. alpha: $-4.8 \pm 5.0, \mathrm{p}<0.001$; beta: $-4.6 \pm 3.6, \mathrm{p}<0.001$; hfb: $1.0 \pm 1.7$, $\mathrm{p}=0.006$. Mean \pm standard deviation, t-test). Spectral power differs significantly between foot and hand movements in the beta, gamma, and high frequency bands (beta: $1.2 \pm$ 2.2, $\mathrm{p}=0.014$; gamma: $-0.6 \pm 1.2, \mathrm{p}=0.028$; hfb: $-0.9 \pm 1.1, \mathrm{p}<0.001)$.

Interestingly, spectral power in the STN signals during movements displayed an almost opposite behavior. Theta, alpha, and low beta spectral power increase during movement compared to rest, while the higher beta power increased slightly or did not change (Foot. delta: $2.0 \pm 1.7, p<0.001$; theta: $2.3 \pm 2.9, p<0.001$; alpha: $1.3 \pm 2.3, p=0.010$; gamma: $0.2 \pm 0.2, p<0.001$; hfb: $0.1 \pm 0.0, p<0.001$. Hand. delta: $2.6 \pm 2.3, p<0.001$; theta: $4.1 \pm$ 5.8, $\mathrm{p}=0.002$; alpha: $5.5 \pm 11.8, \mathrm{p}=0.029$; gamma: $0.4 \pm 0.8, \mathrm{p}=0.012$; hfb: $0.1 \pm 0.2$, $\mathrm{p}<0.001)$. Furthermore, foot and hand movements differ in theta, alpha, and hfb power in the subcortical signals (theta: $-1.7 \pm 3.6, p=0.023$; alpha: $-4.2 \pm 9.8, p=0.043$; hfb: -0.1 $\pm 0.2, p=0.023)$.

We also analyzed frequencies with the most prominent changes during limb movements. In the ECoG signals, we measured frequencies with the maximal desynchronization during hand and foot movements versus rest (Figure 3B). Given that the STN field potentials were inverted and showed increases in spectral power, we instead measured 
medRxiv preprint doi: https://doi.org/10.1101/2022.01.04.22268757; this version posted January 6, 2022. The copyright holder for this preprint (which was not certified by peer review) is the author/funder, who has granted medRxiv a license to display the preprint in perpetuity. All rights reserved. No reuse allowed without permission.

frequencies with maximal synchronizations (Figure 3C). In most cases, maximal cortical desynchronization occurred at similar frequencies during foot versus hand movements $(14.4 \pm 6.6 \mathrm{~Hz}$ and $15.8 \pm 6.7 \mathrm{~Hz}$, respectively, mean \pm standard deviation, $\mathrm{p}=0.460$, paired t-test). In contrast, maximal synchronization in the STN region occurred at lower peak frequencies during foot versus hand movements $(4.2 \pm 2.9 \mathrm{~Hz}$ and $6.0 \pm 3.3 \mathrm{~Hz}$ respectively, $p=0.046$ ).
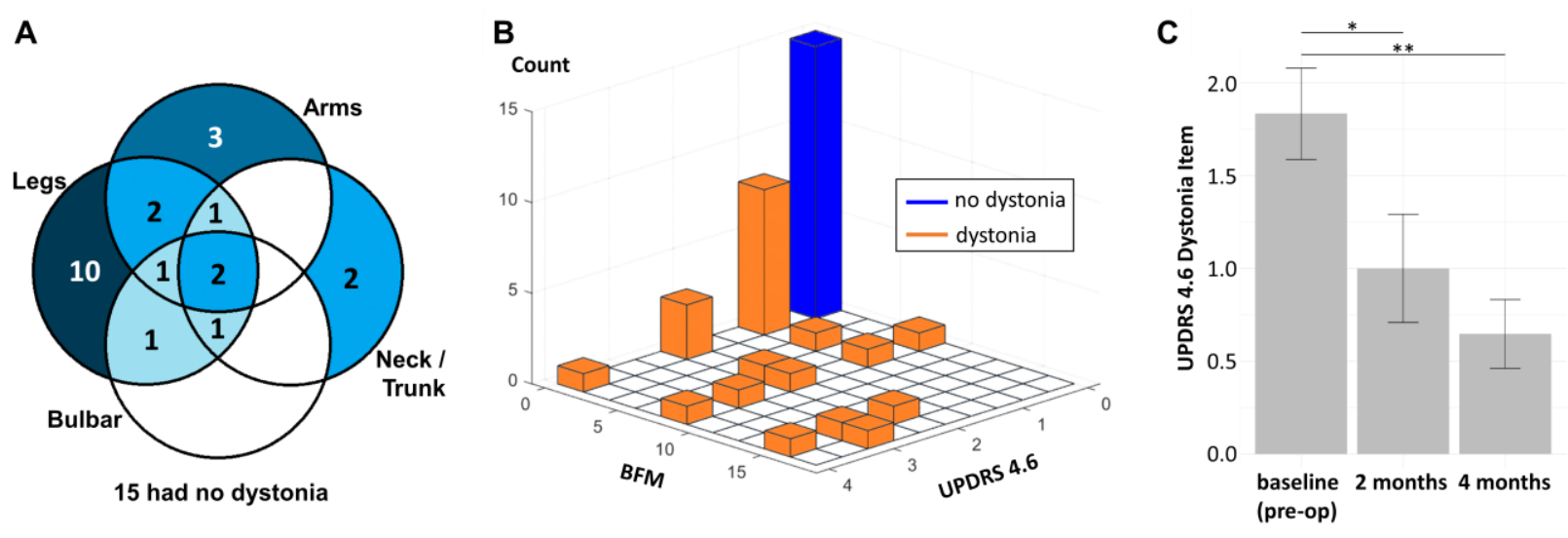

FIGURE 4. Prevalence and anatomic distribution of dystonia in PD participants evaluated for DBS surgery during baseline visit, and clinical outcomes. (A) Venn diagram of anatomic distribution of dystonia clustered into four groups (arms, legs, bulbar, neck/trunk). The number in each circle intersection denotes the number of participants who had the corresponding parts affected by the dystonia (self-reported or discovered by Burke-Fahn-Marsden dystonia rating scale). Fifteen out of 38 participants had no dystonia at baseline. (B) Three-dimensional histogram of UPDRS dystonia item 4.6 (painful dystonia scale) versus BFM total score. Orange bars denote participants with dystonia and the blue bar denotes participants with no dystonia. (C) Dystonia motor outcomes following DBS. Error bars indicate standard error. Both 2 months and 4 months are significant from baseline $(p=0.002 ; p<0.001)$.

\section{Dystonia prevalence and clinical features}

Dystonia status was assessed based on participant report (UPDRS item 4.6), the BFM score at a motor screening visit, and neurological examination during DBS surgery. In total, dystonia was present based on history, examination, or both in 23 of 38 participants (61\%). Dystonia occurred most, but not exclusively, in the foot (18/23, 78\%) (Figure 4A). Among participants with dystonia based on history, 8 of 16 did not manifest subjective or visible dystonia "off" meds during surgery (50\%). Although UPDRS item 4.6 correlates linearly with BFM total score $(F=8.337, p=0.006$, adjusted $\mathrm{R}$-square $=0.114)$ (Figure 4B), many participants did not manifest dystonia "off" medications at their screening visit (10/38, 26\%). Interim analyses provide evidence that unilateral STN DBS improves dystonia symptoms, based on changes in UPDRS item 4.6 at 2- and 4-months post-op versus pre-op baseline $(F=24.127, p<0.001$, linear mixed model with dependent variable UPDRS 4.6 and fixed effect time, subject-specific random intercept) (Figure 4C). 
medRxiv preprint doi: https://doi.org/10.1101/2022.01.04.22268757; this version posted January 6, 2022. The copyright holder for this preprint (which was not certified by peer review) is the author/funder, who has granted medRxiv a license to display the preprint in perpetuity. All rights reserved. No reuse allowed without permission.

\section{Electrophysiological biomarkers of dystonia in PD}

All patients were classified as having dystonia or not based on UPDRS item 4.6, BFM, or a surgical exam. In each case, wavelet spectrum averages across dystonia and nodystonia groups for each channel were plotted for the resting state, hand, and foot movements (Figure 5). During foot movement, we observed statistically significant differences $(p<0.05)$ between STN low frequency power in PD patients with vs without dystonia when using BFM (4-12 Hz) and surgical exam $(4-11 \mathrm{~Hz})$ but not UPDRS. Significant differences $(p<0.05)$ in STN power were also observed during hand movement when using surgical exam classification $(5-15 \mathrm{~Hz})$. No significant differences in STN power were observed during rest for any dystonia classification. Furthermore, there was a significant difference $(p<0.05)$ in cortical spectral power during hand movement using surgical exam classification $(3-25 \mathrm{~Hz})$. Otherwise, there were no observed differences in cortical spectral power between PD patients with and without dystonia.

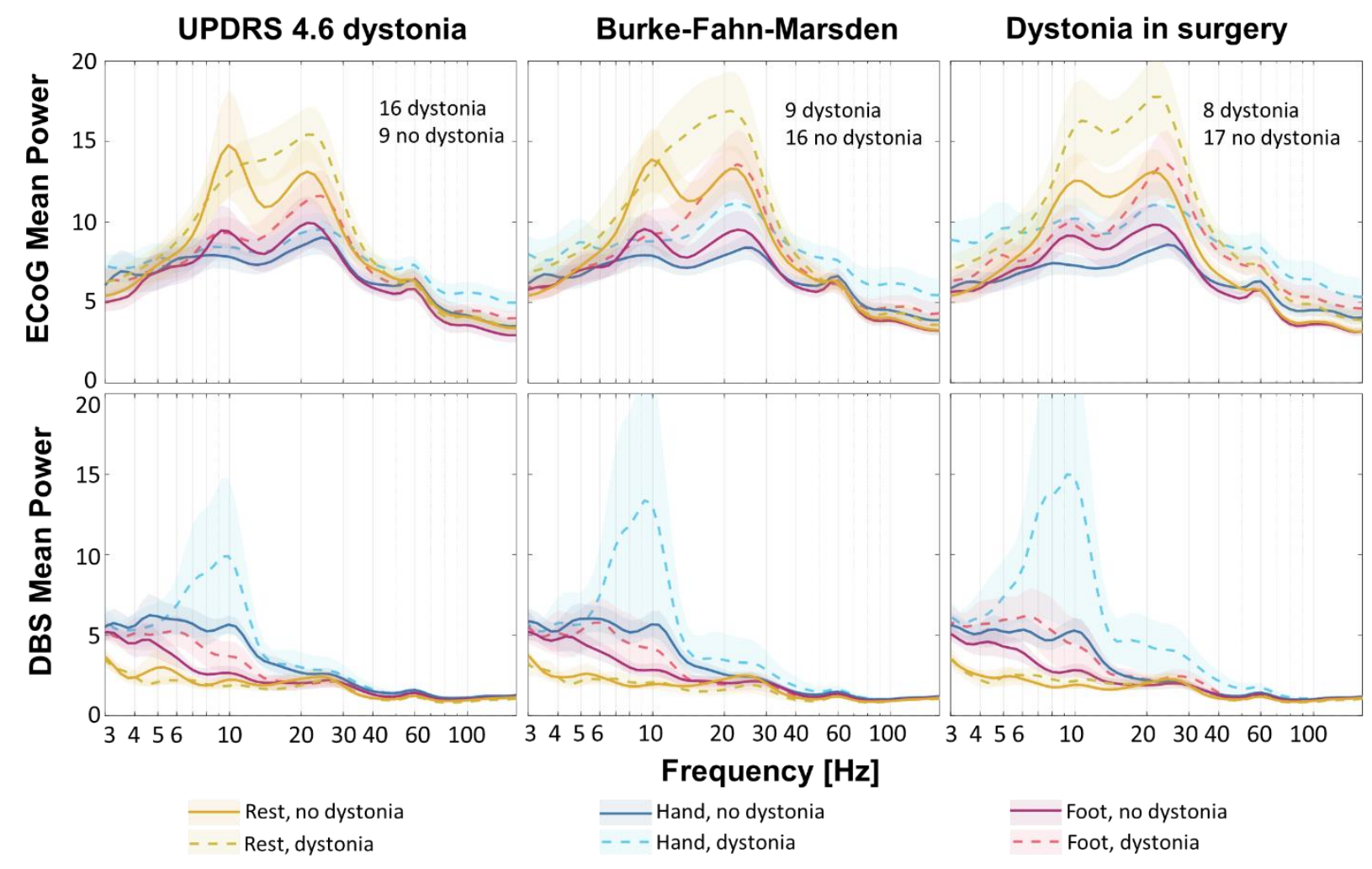

FIGURE 5. Cortical and subcortical spectral perturbations during rest, hand, and foot movements in PD participants with versus without dystonia. Spectral power from all electrode contacts over ipsilateral sensorimotor cortex (first row) and STN region (second row) are categorized by presence/absence of dystonia historically (UPDRS 4.6), at pre-operative baseline assessment (BFM), and during DBS surgery (mean \pm standard error). Dashed and solid lines represent average spectral power in PD patients with and without dystonia, respectively. Yellow, blue, and red colors correspond to rest, hand, and foot movements. 
medRxiv preprint doi: https://doi.org/10.1101/2022.01.04.22268757; this version posted January 6, 2022. The copyright holder for this preprint (which was not certified by peer review) is the author/funder, who has granted medRxiv a license to display the preprint in perpetuity. All rights reserved. No reuse allowed without permission.

\section{DISCUSSION}

Here we report three primary findings, each related to neural activity in the theta and alpha frequency ranges. First, we provide evidence that PD patients with dystonia display greater theta and alpha power in STN during self-paced, repetitive contralateral hand and foot movements, compared to PD patients without dystonia (Figure 5). Second, regardless of dystonia status, repetitive contralateral foot movements increase subcortical spectral power predominantly in the theta range, whereas contralateral hand movements yielded the greatest synchrony at alpha frequencies (Figure 3). Finally, sensorimotor cortex and basal ganglia field potentials differ markedly during voluntary movements, with beta desynchronization in cortex and broadband low frequency activation in the STN (Figure 3).

\section{Dystonia pathophysiology in subcortical versus cortical field potentials}

PD and primary dystonia result from network-level dysfunctions involving interconnected brain regions [50, 51, 4, 52, 53]. Both have been associated with decreased inhibition, abnormal plasticity, and aberrant sensorimotor integration in cortex, brainstem, thalamus, and cerebellum $[54,55,56,57,58,59,60]$. Although we are unaware of prior studies examining intracranial electrophysiology in PD patients with and without dystonia, studies on primary dystonia suggest excessive theta and alpha power in basal ganglia at rest compared to PD (regardless of dystonia status in PD patients). Although we did not identify similar differences in our sample at rest, we observed excessive theta and alpha power during repetitive limb movements in PD patients with dystonia versus without. These electrophysiological findings are consistent with clinical phenomena of dystonia, i.e., worsening symptom severity during voluntary movements. Movement-related theta and alpha range synchronization were more robust in patients who manifested dystonia in surgery versus based upon historical report alone (Figure 5). This is likely due to the simultaneous acquisition of the LFPs and surgical dystonia exam. Changes related to dystonia were less prominent in cortex, which parallels findings from prior studies comparing primary dystonia and PD [23]. Although group level spectral differences were observed between PD patients with and without dystonia, there was considerable overlap between the two groups, perhaps because of similarities related to common elements of underlying PD pathophysiology.

\section{Low frequency STN activity during upper and lower limb movements}

One curiosity of dystonia is its specific somatotopic distribution across various primary and secondary etiologies. Dystonia from PD often involves the foot initially and then spreads elsewhere with disease progression, whereas other forms of dystonia display distinct somatotopy and progression over time [61, 62]. This anatomic specificity suggests that circuit dysfunction related to dystonia might display a somatotopic arrangement, as well. We therefore focused our analyses on voluntary limb movements in addition to the resting state. In the STN, repetitive limb movements yielded broadband increases in low frequency power, with foot and hand movements manifesting primarily in the theta and alpha frequency ranges, respectively. Of note, we did not observe similar changes in the hand region of sensorimotor cortex, which instead displayed less specific 
medRxiv preprint doi: https://doi.org/10.1101/2022.01.04.22268757; this version posted January 6, 2022. The copyright holder for this preprint (which was not certified by peer review) is the author/funder, who has granted medRxiv a license to display the preprint in perpetuity. All rights reserved. No reuse allowed without permission.

alpha and beta desynchronization. Hand movements alone yielded increases in cortical hfb power, which confirms placement of the electrocorticography strip over the hand knob of sensorimotor cortex (Figure 3).

Although spectral power in the beta range is considerably greater in cortex than STN at rest, the subcortical recording sites displayed greater variation and specificity in the theta and alpha range during upper and lower extremity movements. Previous studies have implicated low frequency activity in STN during lower limb movements, as well [30, 41]. Some have argued that low frequency signals in basal ganglia represent movement artifacts [41], but we and others contend that they likely represent neural activity [30]. Although increases in subcortical spectral power during limb movements occur at relatively low frequencies, this activity is still considerably faster than the periodicity of the movements themselves in the periphery. Furthermore, we did not identify similar low frequency synchronization in cortical signals acquired in parallel into the same recording amplifier. Future studies should further examine the temporal dynamics of basal ganglia field potentials during voluntary, naturalistic, repetitive limb movements, as the results have implications for implementing adaptive DBS therapy.

\section{Resting beta power is greater in sensorimotor cortex than in STN}

Consistent with prior studies, we found prominent beta band frequencies at rest in cortex, along with large desynchronizations during voluntary movements [63]. Interestingly, the peak beta frequency in cortex systematically decreased from premotor and motor areas to sensory areas, especially across the central sulcus (Figure 2). Similar peak-frequency gradients have been reported with magnetoencephalography (MEG) recordings [64, 65, 66]. Resting beta power was also observed in STN, although it was considerably smaller in power and present less consistently (Figure 2). STN signals were also more enriched in spectral content at lower frequencies, both at rest and during movements (Figure 3). At odds with some prior literature, we observed little beta desynchronization in STN during the blocks of repetitive movements in our experimental paradigm. We speculate this may be due either to our paradigm studying repetitive, naturalistic self-paced repetitive movements instead of cued movements or to beta-rebound phenomena. Regardless, beta desynchronization in cortex was more robust and sustained during movement epochs versus in STN.

\section{Prevalence of dystonia in PD}

Dystonia is an underrecognized symptom of PD, with historical prevalence estimates at approximately $30 \%$ [1]. Although we observed dystonia during surgery in $31 \%$ of our sample, other available measures indicate a total prevalence of at least $61 \%$ at the time of enrollment. Underestimates could arise from the fluctuating nature of dystonia symptoms, lack of data capture in routine assessment measures, and/or lack of explicit recognition of dystonia symptoms by patients and/or clinicians. Another contributor is likely sampling bias, such that PD patients with dystonia are more likely to receive DBS than those without. One study reported $71 \%$ dystonia prevalence in PD patients undergoing DBS surgery [11]. This relatively high prevalence among DBS patients emphasizes the importance of further electrophysiology studies on PD-related dystonia. 
medRxiv preprint doi: https://doi.org/10.1101/2022.01.04.22268757; this version posted January 6, 2022. The copyright holder for this preprint (which was not certified by peer review) is the author/funder, who has granted medRxiv a license to display the preprint in perpetuity.

\section{Translational significance}

Lower extremity symptoms (freezing of gait, shuffling, balance problems, bradykinesia, dystonia) limit mobility and often improve with DBS, but they can be more resistant to therapy compared to symptoms in the arms. Better therapies for gait and balance dysfunction are major unmet needs for PD patients. Subcortical spectral perturbations with specificity for different motor behaviors could eventually yield new strategies for closed loop DBS. Identification of walking versus rest or dystonia versus no dystonia in real time might allow adaptive delivery of stimulation parameters that optimize motor performance with greater specificity than open loop DBS. Our study uses simultaneous cortical and subcortical field potential recordings, including the increased spatial resolution of directional DBS leads, in a relatively large sample $(n=25)$ to provide new knowledge about activity in human brain circuits during repetitive limb movements. Study limitations include the time and physical constraints of data collection during surgery and the potential for microlesion effects related to DBS lead implant. Future studies should further evaluate these phenomena with chronic recordings from DBS devices with integrated stimulation and sensing capabilities [67].

\section{CONCLUSIONS}

Intracranial recordings of PD patients with dystonia are characterized by increased spectral power in the theta and alpha frequency bands during repetitive voluntary movements in STN but not in sensorimotor cortex. Furthermore, repetitive limb movements elicit broadband increases in low frequency power in the STN region, with predominant theta and alpha activity during contralateral foot and hand movements, respectively. In contrast, cortical recording sites show prominent and sustained beta desynchronization during limb movements, with less specificity for dystonia status or limb movement type. PD-related dystonia and other lower extremity symptoms are somewhat neglected as research topics in electrophysiological studies. These efforts promise to shed light on dystonia pathophysiology and to guide implementation of emerging device technologies such as directional and closed-loop stimulation.

\section{ACKNOWLEDGMENTS}

We would like to thank Matthew J. Nelson for scientific discussions and advice. 


\section{REFERENCES}

[1] D. Kidron and E. Melamed, "Forms of dystonia in patients with Parkinson's disease," Neurology, vol. 37, no. 6, pp. 1009-1011, 1987.

[2] E. Tolosa and Y. Compta, "Dystonia in Parkinson's disease," Journal of Neurology, pp. VII/7-VII/13, 2006.

[3] E. Tolosa, M. J. Marti and Y. Compta, "Dystonic symptoms associated with parkinsonian disorders," in Handbook of Dystonia, 2012, pp. 276-296.

[4] A. S. Shetty, K. P. Bhatia and A. E. Lang, "Dystonia and Parkinson's disease: What is the relationship?," Neurobiology of disease, vol. 132, 2019.

[5] A. J. Lees, H. R. J. and G. M. Stern, "Kinesigenic foot dystonia as a presenting feature of Parkinson's disease," Journal of Neurology, Neurosurgery, and Psychiatry, vol. 47, no. 8, p. 885, 1984.

[6] P. A. LeWitt, R. S. Burns and R. P. Newman, "Dystonia in Untreated Parkinsonism," Clinical Neuropharmacology, vol. 9, no. 3, pp. 293-297, 1986.

[7] J. Jankovic and R. Tintner, "Dystonia and parkinsonism," Parkinsonism \& Related Disorders, vol. 8, no. 2, pp. 109-121, 2001.

[8] O. S. Gershanik, "Early onset parkinsonism," Frontiers in Bioscience-Landmark, vol. 8, no. 6, pp. 568-578, 2003.

[9] O. S. Gershanik and A. Leist, "Juvenile onset Parkinson's disease," Advances in Neurology, pp. 213-216, 1987.

[10] A. Schrag and N. Quinn, "Dyskinesias and motor fluctuations in Parkinson's disease: A communitybased study," Brain, vol. 123, no. 11, pp. 2297-2305, 2000.

[11] P. Krack, A. Batir, N. Van Blercom, S. Chabardes, V. Fraix, C. Ardouin, A. Koudsie, P. D. Limousin, A. Benazzouz, J. F. LeBas, A.-L. Benabid and P. Pollak, "Five-Year Follow-up of Bilateral Stimulation of the Subthalamic Nucleus in Advanced Parkinson's Disease," The New England Journal of Medicine, pp. 1925-1934, 2003.

[12] P. Krack, P. Pollak, P. Limousin, A. Benazzouz, G. Deuschl and A.-L. Benabid, "From off-period dystonia to peak-dose chorea: the clinical spectrum of varying subthalamic nucleus activity," Brain, vol. 122, pp. 1133-1146, 1999.

[13] O. Detante, L. Vercueil, P. Krack, S. Chabardes, A.-L. Benabid and P. Pollak, "Off-period dystonia in Parkinson's disease but not generalized dystonia is improved by high-frequency stimulation of the subthalamic nucleus," Advances in neurology, vol. 94, pp. 309-314, 2004.

[14] W.-J. Neumann, R. S. Turner, B. Blankertz, T. Mitchell, A. A. Kuhn and R. M. Richardson, "Toward Electrophysiology-Based Intelligent Adaptive Deep Brain Stimulation for Movement Disorders," Neurotherapeutics, vol. 16, pp. 105-118, 2019. 
[15] P. Silberstein, A. A. Kuhn, A. Kupsch, T. Trottenberg, J. K. Krauss, J. C. Wohrle, P. Mazzone, Insola, Angelo, V. Di Lazzaro, A. Oliviero, T. Aziz and P. Brown, "Patterning of globus pallidus local field potentials differs between Parkinson's disease and dystonia," Brain, vol. 126, no. 12, pp. 25972608, 2003.

[16] C. C. Chen, A. A. Kuhn, T. Trottenberg, A. Kupsch, G.-H. Schneider and P. Brown, "Neuronal activity in globus pallidus interna can be synchronized to local field potential activity over $3-12 \mathrm{~Hz}$ in patients with dystonia," Experimental Neurology, vol. 202, pp. 480-486, 2006.

[17] X. Liu, S. Wang, J. Yianni, D. Nandi, P. G. Bain, R. Gregory, J. F. Stein and T. Z. Aziz, "The sensory and motor representation of synchronized oscillations in the globus pallidus in patients with primary dystonia," Brain, vol. 131, pp. 1562-1573, 2008.

[18] W.-J. Neumann, A. Horn, S. Ewert, J. Huebl, C. Brucke, C. Slentz, G.-H. Schneider and A. A. Kuhn, "A localized pallidal physiomarker in cervical dystonia," Annals of neurology, vol. 82, no. 6, pp. 912924, 2017.

[19] E. Barow, W.-J. Neumann, C. Brucke, J. Huebl, A. Horn, P. Brown, J. K. Krauss, G.-H. Schneider and A. A. Kuhn, "Deep brain stimulation suppresses pallidal low frequency activity in patients with phasic dystonic movements," Brain, vol. 137, no. 11, pp. 3012-3024, 2014.

[20] D. Piña-Fuentes, J. C. van Zijl, J. M. C. van Dijk, S. Little, G. Tinkhauser, M. D. Oterdoom, M. A. Tijssen and M. Beudel, "The characteristics of pallidal low-frequency and beta bursts could help implementing adaptive brain stimulation in the parkinsonian and dystonic internal globus pallidus," Neurobiology of Disease, vol. 121, pp. 47-57, 2019.

[21] D. D. Wang, C. de Hemptinne, S. Miocinovic, J. L. Ostrem, N. B. Galifianakis, M. San Luciano and P. A. Starr, "Pallidal Deep-Brain Stimulation Disrupts Pallidal Beta Oscillations and Coherence with Primary Motor Cortex in Parkinson's Disease," Neurobiology of Disease, vol. 38, no. 19, pp. 45564568, 2018.

[22] R. Lofredi, W.-J. Neumann, C. Brucke, J. Heubl, J. K. Krauss, G.-H. Schneider and A. A. Kuhn, "Pallidal beta bursts in Parkinson's disease and dystonia," Movement Disorders, vol. 34, no. 3, pp. 420-424, 2019.

[23] D. Piña-Fuentes, v. D. J. M. C., D. G., J. C. van Zijl, T. van Laar, M. A. J. Tijssen and M. Beudel, "Direct comparison of oscillatory activity in the motor system of Parkinson's disease and dystonia: A review of the literature and meta-analysis," Clinical Neurophysiology, vol. 130, no. 6, pp. 917-924, 2019.

[24] D. D. Wang, C. de Hemptinne, S. Miocinovic, S. E. Qasim, A. M. Miller, J. L. Ostrem, N. B. Galifianakis, M. San Luciano and P. A. Starr, "Subthalamic local field potentials in Parkinson's disease and isolated dystonia: An evaluation of potential biomarkers," Neurobiology of disease, vol. 89, pp. 213-222, 2016.

[25] X. Geng, J. Zhang, Y. Jiang, K. Ashkan, T. Foltynie, P. Limousin, L. Zrinzo, A. Green, T. Aziz, P. Brown and S. Wang, "Comparison of oscillatory activity in subthalamic nucleus in Parkinson's disease and dystonia," Neurobiology of disease, vol. 98, pp. 100-107, 2017.

[26] W.-J. Neumann, J. Huebl, C. Brucke, M. H. Ruiz, A. Kupsch, G.-H. Schneider and A. A. Kuhn, "Enhanced low-frequency oscillatory activity of the subthalamic nucleus in a patient with dystonia," Movement Disorders, vol. 27, no. 8, pp. 1063-1066, 2012. 
medRxiv preprint doi: https://doi.org/10.1101/2022.01.04.22268757; this version posted January 6, 2022. The copyright holder for this preprint (which was not certified by peer review) is the author/funder, who has granted medRxiv a license to display the preprint in perpetuity. All rights reserved. No reuse allowed without permission.

[27] A. L. Crowell, E. S. Ryapolova-Webb, J. L. Ostrem, N. B. Galifianakis, S. Shimamoto, D. A. Lim and P. A. Starr, "Oscillations in sensorimotor cortex in movement disorders: an electrocorticography study," Brain, vol. 135, no. 2, pp. 615-630, 2012.

[28] S. Miocinovic, C. de Hemptinne, S. Qasim, J. L. Ostrem and P. A. Starr, "Patterns of Cortical Synchronization in Isolated Dystonia Compared With Parkinson Disease," JAMA Neurology, vol. 72, no. 11, pp. 1244-1251, 2015.

[29] R. S. Eisinger, J. N. Cagle, E. Opri, J. Alcantara, S. Cernera, K. D. Foote, M. S. Okun and A. Gunduz, "Parkinsonian Beta Dynamics during Rest and Movement in the Dorsal Pallidum and Subthalamic Nucleus," Journal of Neuroscience, vol. 40, no. 14, pp. 2859-2867, 2020.

[30] D. D. Wang and J. T. Choi, "Brain Network Oscillations During Gait in Parkinson's Disease," Frontiers in Human Neuroscience, 2020.

[31] A. Singh, R. C. Cole, A. I. Espinoza, D. Brown, J. F. Cavanagh and N. Narayanan, "Frontal theta and beta oscillations during lower-limb movement in Parkinson's disease," Clinical Neurophysiology, vol. 131, no. 3, pp. 694-702, 2021.

[32] T. H. Petersen, M. Willerslev-Olsen, B. A. Conway and J. B. Nielsen, "The motor cortex drives the muscles during walking in human subjects," The journal of physiology, vol. 590, no. 10, pp. 24432452, 2012.

[33] M. E. Spedden, J. T. Choi, J. B. Nielsen and S. S. Geertsen, "Corticospinal control of normal and visually guided gait in healthy older and younger adults," Neurobiology of aging, vol. 78, pp. 29-41, 2019.

[34] J. M. Shine, A. M. A. Handojoseno, T. N. Nguyen, Y. Tran, S. L. Naismith, H. Nguyen and S. J. G. Lewis, "Abnormal patterns of theta frequency oscillations during the temporal evolution of freezing of gait in Parkinson's disease," Clinical Neurophysiology, vol. 125, no. 3, pp. 569-576, 2014.

[35] Y. Miron-Shahar, J. W. Kantelhardt, A. Grinberg, S. Hassin-Baer, I. Blatt, R. Inzelberg and M. Plotnik, "Excessive phase synchronization in cortical activation during locomotion in persons with Parkinson's disease," Parkinsonism \& related disorders, vol. 65, pp. 210-216, 2019.

[36] G. Pfurtscheller, C. Neuper, C. Andrew and G. Edlinger, "Foot and hand area mu rhythms," International Journal of Psychophysiology, vol. 26, pp. 121-135, 1997.

[37] G. Tinkhauser, S. A. Shah, P. Fischer, K. Peterman, I. Debove, K. Nygyuen, A. Nowacki, F. Torrecillos, S. Khawaldeh, H. Tan, A. Pogosyan, M. Scheupbach, C. Pollo and P. Brown, "Electrophysiological differences between upper and lower limb movements in the human subthalamic nucleus," Clinical Neurophysiology, vol. 130, no. 5, pp. 727-738, 2019.

[38] S. Khawaldeh, G. Tinkhauser, S. A. Shah, K. Peterman, I. Debove, K. Nygyuen, A. Nowacki, M. L. Lachenmayer, M. Scheupbach, C. Pollo, P. Krack, M. Woolrich and P. Brown, "Subthalamic nucleus activity dynamics and limb movement prediction in Parkinson's disease," Brain, vol. 143, no. 2, pp. 582-596, 2020.

[39] C. Neuper and G. Pfùrtscheller, "Evidence for distinct beta resonance frequencies in human EEG related to specific sensorimotor cortical areas," Clincal Neurophysiology, vol. 112, no. 11, pp. 20842097, 2001.

[40] E. J. Quinn, Z. Blumenfeld, A. Velisar, M. M. Koop, L. A. Shreve, M. H. Trager, B. C. Hill, C. Kilbane, J. M. Henderson and H. Brontë-Stewart, "Beta oscillations in freely moving Parkinson's subjects are 
medRxiv preprint doi: https://doi.org/10.1101/2022.01.04.22268757; this version posted January 6, 2022. The copyright holder for this preprint (which was not certified by peer review) is the author/funder, who has granted medRxiv a license to display the preprint in perpetuity. All rights reserved. No reuse allowed without permission.

attenuated during deep brain stimulation," Movement Disorders, vol. 30, no. 13, pp. 1750-1758, 2015.

[41] F. Hell, A. Plate, J. H. Mehrkens and K. Bötzel, "Subthalamic oscillatory activity and connectivity during gait in Parkinson's disease," Neuroimage: Clinical, vol. 19, pp. 396-405, 2018.

[42] G. Arnulfo, N. G. Pozzi, C. Palmisano, A. Leporini, A. Canessa, J. Brumberg, G. Pezzoli, C. Matthies, J. Volkmann and I. U. Isaias, "Phase matters: A role for the subthalamic network during gait," PLoS One, vol. 13, no. 6, 2018.

[43] S. G. Heideman, E. S. te Woerd and P. Praamstra, "Rhythmic entrainment of slow brain activity preceding leg movements," Clinical Neurophysiology, vol. 126, no. 2, pp. 348-355, 2015.

[44] R. E. Burke, S. Fahn, C. D. Marsden, S. B. Bressman, C. Moskowitz and J. Friendman, "Validity and reliability of a rating scale for the primary torsion dystonias," Neurology, vol. 35, no. 1, pp. 73-77, 1985.

[45] B. Fischl, "FreeSurfer," Neurolmage, vol. 62, no. 2, pp. 774-781, 2012.

[46] A. Horn, N. Li, T. A. Dembek, A. Kappel, C. Boulay, S. Ewert, A. Tietze, A. Husch, T. Perera, W. J. Neumann, M. Reisert, H. Si, R. Oostenveld, C. Rorden, F. C. Yeh, Q. Fang, T. M. Herrington, J. Vorwerk and A. A. Kühn, "Lead-DBS v2: Towards a comprehensive pipeline for deep brainstimulation imaging," Neurolmage, vol. 184, pp. 293-316, 2019.

[47] A. Delorme and S. Makeig, "EEGLAB: an open source toolbox for analysis of single-trial EEG dynamics including independent component analysis," Journal of Neuroscience Methods, vol. 134, pp. 9-21, 2004.

[48] J. Cheng, L. Edwards, M. Maldonado-Molina, K. Komro and K. Muller, "Real Longitudinal Data Analysis for Real People: Building a Good Enough Mixed Model," Statistics in Medicine, vol. 29, pp. 504-520, 2010.

[49] L. Edwards, "Modern Statistical Techniques for the Analysis of Longitudinal Data in Biomedical Research," Pediatric Pulmonology, vol. 30, no. 4, pp. 330-344, 2000.

[50] H. A. Jinnah, V. Neychev and E. J. Hess, "The Anatomical Basis for Dystonia: The Motor Network Model," Tremor and Other Hyperkinetic Movements, vol. 7, no. 506, 2017.

[51] M. M. McGregor and A. B. Nelson, "Circuit Mechanisms of Parkinson's Disease," Neuron, vol. 101, no. 6 , pp. 1042-1056, 2019.

[52] D. Caligiore, R. C. Helmich, M. Hallett, A. A. Moustafa, L. Timmermann, I. Toni and G. Baldassarre, "Parkinson's disease as a system-level disorder," Nature Parkinson's Disease, vol. 2, no. 16025, 2016.

[53] M. R. DeLong and T. Wichmann, "Circuits and Circuit Disorders of the Basal Gangli," Neurological Review, vol. 64, no. 1, pp. 20-24, 2007.

[54] A. Quartarone and M. Hallett, "Emerging concepts in the physiological basis of dystonia," Movement Disorders, vol. 28, no. 7, pp. 958-967, 2013. 
medRxiv preprint doi: https://doi.org/10.1101/2022.01.04.22268757; this version posted January 6, 2022. The copyright holder for this preprint (which was not certified by peer review) is the author/funder, who has granted medRxiv a license to display the preprint in perpetuity. All rights reserved. No reuse allowed without permission.

[55] W.-J. Neumann, A. Jha, A. Bock, J. Buebl, A. Horn, G.-H. Schenider, T. H. Sander, V. Litvak and A. A. Kuhn, "Cortico-pallidal oscillatory connectivity in patients with dystonia," Brain, vol. 138, no. 7, pp. 1894-1906, 2015.

[56] M. Hallett, "Neurophysiology of dystonia: The role of inhibition," Neurobiology of Disease, vol. 42, no. 2, pp. 177-184, 2011.

[57] J. K. H. Tang, E. Moro, N. Mahant, W. D. Hutchison, A. E. Lang, A. M. Lozano and J. O. Dostrovsky, "Neuronal firing rates and patterns in the globus pallidus internus of patients with cervical dystonia differ from those with Parkinson's disease," Journal of Neurophysiology, vol. 98, no. 2, pp. 720-729, 2007.

[58] P. A. Starr, G. M. Rau, V. Davis, W. J. J. Marks, J. L. Ostrem, D. Simmons, N. Lindsey and R. S. Turner, "Spontaneous pallidal neuronal activity in human dystonia: comparison with Parkinson's disease and normal macaque," Journal of Neurophysiology, vol. 93, no. 6, pp. 3165-3176, 2005.

[59] J. L. Vitek, V. Chockkan, J. Y. Zhang, Y. Kaneoke, M. Evatt, M. R. DeLong, S. Triche, K. Mewes, T. Hashimoto and R. A. Bakay, "Neuronal activity in the basal ganglia in patients with generalized dystonia and hemiballismus," Annals of Neurology, vol. 46, no. 1, pp. 22-35, 1999.

[60] J. Guridi and M. Alegre, "Oscillatory Activity in the Basal Ganglia and Deep Brain Stimulation," Movement Disorders, vol. 32, no. 1, pp. 64-69, 2017.

[61] J. Phukan, A. Albanese, T. Gasser and T. Warner, "Primary dystonia and dystonia-plus syndromes: clinical characteristics, diagnosis, and pathogenesis," The Lancet: Neurology, vol. 10, no. 12, pp. 1074-1085, 2011.

[62] A. Albanese, K. Bhatia, S. B. Bressman, M. R. DeLong, S. Fahn, V. S. C. Fung, M. Hallett, J. Jankovic, H. A. Jinnah, C. Klein, A. E. Lang, J. W. Mink and J. K. Teller, "Phenomenology and classification of dystonia: a consensus update," Movement Disorders, vol. 28, no. 7, pp. 863-873, 2014.

[63] J. Barone and H. E. Rossiter, "Understanding the Role of Sensorimotor Beta Oscillations," Frontiers in Systems Neuroscience, vol. 15, no. 655886, 2021.

[64] T. Donoghue, M. Haller, E. J. Peterson, P. Varma, P. Sebastian, R. Gao, T. Noto, A. H. Lara, J. D. Wallis, R. T. Knight, A. Shestyuk and B. Voytek, "Parameterizing neural power spectra into periodic and aperiodic components," Nature Neuroscience, vol. 23, no. 12, pp. 1655-1665, 2020.

[65] G. Niso, C. Rogers, J. T. Moreau, L.-Y. Chen, C. Madjar, S. Das, E. Bock, F. Tadel, A. C. Evans, P. Jolicoeur and S. Baillet, "OMEGA: The Open MEG Archive," Neurolmage, vol. 124, pp. 1182-1187, 2016.

[66] B. Frauscher, N. von Ellenrieder, R. Zelmann, I. Doležalová, L. Minotti, A. Olivier, J. Hall, D. Hoffmann, D. K. Nguyen, P. Kahane, F. Dubeau and J. Gotman, "Atlas of the normal intracranial electroencephalogram: neurophysiological awake activity in different cortical areas," Brain, vol. 141, no. 4, pp. 1130-1144, 2018.

[67] S. Derrey, R. Lefaucheur, N. Chastan, E. Gérardin, D. Hannequin, M. Desbordes and D. Maltête, "Alleviation of off-period dystonia in Parkinson disease by a microlesion following subthalamic implantation," Journal of neurosurgery, vol. 122, no. 6, pp. 1263-1266, 2010. 
medRxiv preprint doi: https://doi.org/10.1101/2022.01.04.22268757; this version posted January 6, 2022. The copyright holder for this preprint

(which was not certified by peer review) is the author/funder, who has granted medRxiv a license to display the preprint in perpetuity.

All rights reserved. No reuse allowed without permission.

[68] S. N. Brosius, C. L. Gonzalez, J. Shuresh and H. C. Walker, "Reversible improvement in severe freezing of gait from Parkinson's disease with unilateral interleaved subthalamic brain stimulation," Parkinsonism \& Related Disorders, vol. 21, no. 12, pp. 1469-1470, 2015.

[69] D. Weiss, M. Walach, C. Meisner, M. Fritz, A. Gharabaghi, C. Plewnia, S. Breit, B. Bender, T. Wächter and R. Krüger, "Combined interleaving stimulation of the subthalamic nucleus (STN) and the substantia nigra pars reticulata ( $\mathrm{SNr}$ ) for freezing of gait: Results of a randomized controlled trial," Basal Ganglia, vol. 3, no. 1, p. 54, 2013.

[70] L. Marsili, M. Bologna, M. Kojovic, A. Berardelli, A. J. Espay and C. Colosimo, "Dystonia in atypical parkinsonian disorders," Parkinsonism \& Related Disorders, vol. 66, pp. 25-33, 2019.

[71] E. Melamed, "Early-morning dystonia: a late side effect of long-term levodopa therapy in parkinson's disease," Archives of neurology, vol. 36, no. 5, pp. 308-310, 1979.

[72] L. Schrock, J. L. Ostrem, R. S. Turner, S. A. Shimamoto and P. A. Starr, "The subthalamic nucleus in primary dystonia: single-unit discharge characteristics," Journal of Neurophysiology, vol. 102, no. 6, pp. 3740-3752, 2009.

[73] M. Weinberger, W. D. Hutchison, M. Alavi, M. Hodaie, A. M. Lozano, E. Moro and J. O. Dostrovsky, "Oscillatory activity in the globus pallidus internus: comparison between Parkinson's disease and dystonia," Clinical neurophysiology, vol. 123, no. 2, pp. 358-368, 2012.

[74] G. Foffani, G. Ardolino, B. Meda, E. M. P. Rampini, E. Caputo, G. Baselli and A. Priori, "Altered subthalamo-pallidal synchronisation in parkinsonian dyskinesias," Journal of Neurology, Neurosurgeru, and Psychiatry, vol. 76, no. 3, pp. 426-428, 2005.

[75] F. Alonso-French, I. Zamarbide, M. Alegre, M. C. Rodriguez-Oroz, J. Guridi, M. Manrique, M. Valencia, J. Artieda and J. A. Obeso, "Slow oscillatory activity and levodopa-induced dyskinesias in Parkinson's disease," Brain, vol. 129, pp. 1748-1757, 2006.

[76] A. Horn, W.-J. Neumann, K. Degen, G.-H. Schneider and A. A. Kuhn, "Toward an electrophysiological "sweet spot" for deep brain stimulation in the subthalamic nucleus," Human brain mapping, vol. 38, no. 7, pp. 3377-3390, 2017.

[77] J. L. Ostrem, M. San Luciano, K. A. Dodenhoff, N. Ziman, L. C. Markun, C. A. Racine, C. de Hemptinne, M. M. Volz, S. L. Heath and P. A. Starr, "Subthalamic nucleus deep brain stimulation in isolated dystonia: A 3-year follow-up study," Neurology, vol. 88, no. 1, pp. 25-35, 2017.

[78] P. Brown, A. Oliviero, P. Mazzone, A. Insola, P. Tonali and V. Di Lazzaro, "Dopamine Dependency of Oscillations between Subthalamic Nucleus and Pallidum in Parkinson's Disease," Journal of Neuroscience, vol. 21, no. 3, pp. 1033-1038, 2001.

[79] C. de Hemptinne, E. S. Ryapolova-Webb, E. L. Air, a. A. Garcia, K. J. Miller, J. G. Ojemann, J. L. Ostrem, N. B. Galifianakis and P. A. Starr, "Exaggerated phase-amplitude coupling in the primary motor cortex in Parkinson disease," PNAS, vol. 110, no. 12, pp. 4780-4785, 2013.

[80] C. de Hemptinne, N. C. Swann, J. L. Ostrem, E. S. Ryapolova-Webb, M. San Luciano, N. B. Galifianakis and P. A. Starr, "Therapeutic deep brain stimulation reduces cortical phase-amplitude coupling in Parkinson's disease," Nature Neuroscience, vol. 18, pp. 779-786, 2015. 
medRxiv preprint doi: https://doi.org/10.1101/2022.01.04.22268757; this version posted January 6, 2022. The copyright holder for this preprint

(which was not certified by peer review) is the author/funder, who has granted medRxiv a license to display the preprint in perpetuity. All rights reserved. No reuse allowed without permission.

[81] J. Hirschmann, T. E. Ozkurt, M. Butz, M. Homburger, S. Elben, C. J. Hartmann, J. Vesper, L. Wojtecki and A. Schnitzler, "Differential modulation of STN-cortical and cortico-muscular coherence by movement and levodopa in Parkinson's disease," Neuroimage, vol. 68, pp. 203-213, 2013.

[82] S. Martin, I. Iturrate, R. Chavarriaga, R. Leeb, A. Sobolewski, A. M. Li, J. Zaldivar, J. Peciu-Florianu, E. Pralong, M. Castro-Jiménez, D. Benninger, F. Vingerhoets, R. T. Knight, B. J. and J. R. Millán, "Differential contributions of subthalamic beta rhythms and $1 / \mathrm{f}$ broadband activity to motor symptoms in Parkinson's disease," npj Parkinson's Disease, 2018.

[83] M. Vissani, C. Palmisano, J. Volkmann, G. Pezzoli, S. Micera, I. U. Isaias and A. Mazzoni, "Impaired reach-to-grasp kinematics in parkinsonian patients relates to dopamine-dependent, subthalamic beta bursts," npj Parkinson's Disease, 2021.

[84] R. Lofredi, H. Tan, W.-J. Neumann, C.-H. Yeh, G.-H. Schneider, A. A. Kühn and P. Brown, "Beta bursts during continuous movements accompany the velocity decrement in Parkinson's disease patients," Neurobiology of Disease, vol. 127, pp. 462-471, 2019.

[85] H. Yu and J. S. Neimat, "The Treatment of Movement Disorders by Deep Brain Stimulation," Neurotherapeutics, vol. 5, no. 1, pp. 26-36, 2008. 